\title{
Some Hybrid Systems of Chiral Schiff Base Zn(II) Complexes and Photochromic Spiropyrans for Environmental Ion Sensing
}

\author{
Takatomo Miura, Takashi Onodera, Shinya Endo, Atsuo Yamazaki, Takashiro Akitsu* \\ Department of Chemistry, Faculty of Science, Tokyo University of Science, Tokyo, Japan \\ Email: ${ }^{*}$ akitsu@rs.kagu.tus.ac.jp
}

Received 24 June 2014; revised 4 August 2014; accepted 20 August 2014

Copyright $@ 2014$ by authors and Scientific Research Publishing Inc.

This work is licensed under the Creative Commons Attribution International License (CC BY).

http://creativecommons.org/licenses/by/4.0/

(c) (i) Open Access

\section{Abstract}

This is a review article including our recent results and some previous photo functional hybrid system having potential applications for environmental ion sensing. We have prepared several new and known chiral Schiff base Zn(II) complexes and measured (and also calculated) absorption and fluorescence spectra for sole complexes. After assembling hybrid systems with 1,3,3-trimethylindolino-6'-nitrobenzopyrylospiran (SP) in methanol solutions, we measured spectral changes before and after alternate irradiation of UV and visible light. Intensity of fluorescence spectra for pale yellow $\mathrm{Zn}$ (II) complexes $\left(\lambda_{\mathrm{em}}=450 \mathrm{~nm}, \lambda_{\mathrm{ex}}=270\right.$ and $\left.360 \mathrm{~nm}\right)$ was quenched by colorless $S P$ $\left(\lambda_{\mathrm{em}}=533 \mathrm{~nm}, \lambda_{\mathrm{ex}}=612 \mathrm{~nm}\right)$. After UV light irradiation to form purple merocyanine (MC), photoisomerization resulted in changes of the intensity of absorption spectra as well as fluorescence spectra. Thus the hybrid systems could successfully act as molecular logic circuit by input (excitation by light) and output (intensity of fluorescence peaks). Moreover, we investigated concentration dependence of doped $\mathrm{Zn}$ (II) and $\mathrm{Cu}$ (II) ions to confirm quenching of intensity of fluorescence peaks by Zn(II) and Cu(II) MC complexes for metal ion sensing in solutions.

\section{Keywords}

Zinc(II) Complexes, Spiropyran, Chirality, Fluorescence, Ion Sensing

\section{Introduction}

Many machines incorporate electronic components and integrate circuits for their appropriate functionality, which are essential for modern society [1]. Besides conventional miniaturization of logic circuits made of silicon

\footnotetext{
${ }^{*}$ Corresponding author.
}

How to cite this paper: Miura, T., Onodera, T., Endo, S., Yamazaki, A. and Akitsu, T. (2014) Some Hybrid Systems of Chiral Schiff Base Zn(II) Complexes and Photochromic Spiropyrans for Environmental Ion Sensing. American Journal of Analytical Chemistry, 5, 751-765. http://dx.doi.org/10.4236/ajac.2014.512084 
semiconductors, new attention has been attracted to the molecular logic circuits using molecules and molecular assemblies as next-generation high-performance logic circuits [2] [3]. The response speed by using an optical signal is expected to exceed conventional electrical signals, which is significant point for next-generation research and design of molecular logic circuits for an optical signal. In designing logic circuits optical organic molecules [4]-[7], biomolecules (DNA [8] [9] and proteins [10]-[12]), and organic/inorganic hybrid materials [13], especially metal complexes [14] have been employed. Containing photochromic dyes showing their color changes by photoisomerization and functional metal complexes may be one of the promising strategies. In this context, some ideas for constructing logic circuits based on molecular assemblies have been proposed by using metal complexes and photochromic dyes. Great attention has been paid to use weak intermolecular interactions between each component of multifunctional logic circuits of molecular assemblies.

Previously, we have proposed "photoresponsive solvatochromism" [15] in hybrid system consisting of azobenzene derivatives and chiral Schiff base $\mathrm{Ni}(\mathrm{II}), \mathrm{Cu}(\mathrm{II})$, or $\mathrm{Zn}(\mathrm{II})$ complexes showing various stereochemical changes (by thermal phase transition), paramagnetism in solutions, and potential functions as chiral catalysts. Additionally, we have reported that increasing optical anisotropy of not only azobenzene but also chiral Schiff base complexes after polarized UV (and visible) light irradiation was detected by polarized electronic and IR spectroscopy [16]. In general, molecular orientation (long-axis) of azobenzene is gradually aligned to perpendicular to the direction of electric vector of polarized UV light accompanying with reorientation or photoisomerization to the cis-form.

In this work, we have prepared three new and one known Schiff base Zn(II) complexes, Zn-secBu, Zncyclohexyl, Zn-2-naphtyl, and Zn-1-phenyl (Figure 1) and have investigated their absorption and fluorescence spectra sole components and hybrid systems with photochromic 1,3,3-trimethylindolino-6'-nitrobenzopyrylospiran (SP) [17]-[20] before and after UV or visible light irradiation. In addition, we have constructed threecomponent hybrid systems of Schiff base Zn(II) complexes with SP, and Zn(II) or Cu(II) ions in methanol solutions. Moreover, we have also investigated their absorption and fluorescence spectra before and after UV or visible light irradiation to discuss spectral changes of the intensity of fluorescence bands of $\mathrm{Zn}$ (II) complexes and/ or SP (MC) by doping Zn(II) or $\mathrm{Cu}(\mathrm{II})$ ions in order for metal ion sensing [21]-[23] by concentration of doped metal ions.

\section{Experimental}

\subsection{Materials}

All reagents including chiral amines are products of Wako or TCI. Other chemicals were analytical pure and were used as received without further purification. Solvents were used as received from Kanto or Aldrich with

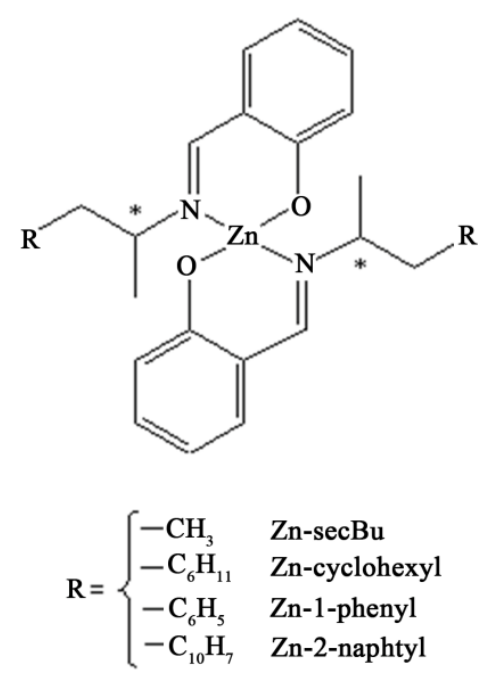

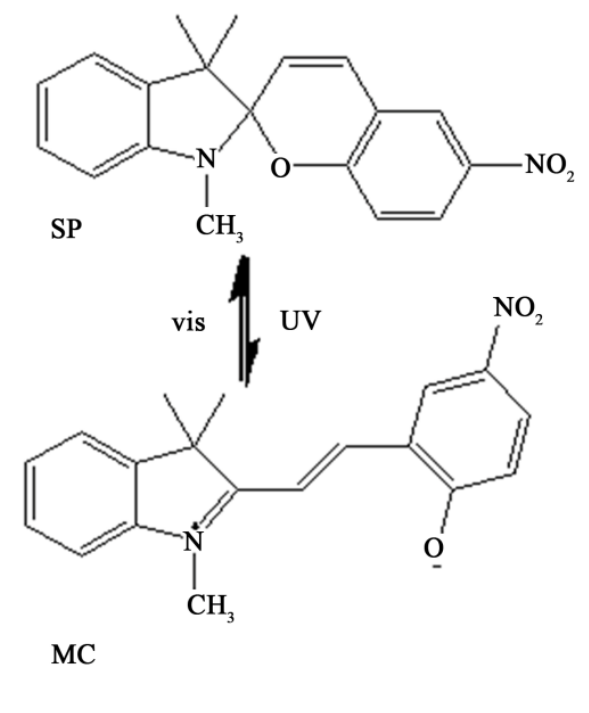

Figure 1. Structures of chiral Schiff base Zn(II) complexes and photoisomerization of SP (MC). 
out further purification or drying. The known complex [24] [25] (Zn-1-phenyl having R-1-phenylethylamine moiety) was prepared according to the literature procedure.

\subsection{Synthesis of $\mathrm{Zn}-\mathrm{secBu}$}

To a solution of salicylaldehyde $(0.48 \mathrm{~g}, 4.0 \mathrm{mmol})$ dissolved in methanol $(70 \mathrm{~mL}), S$-sec-butylamine $(0.51 \mathrm{~g}$, $4.0 \mathrm{mmol}$ ) was added dropwise and stirred at $313 \mathrm{~K}$ for $2 \mathrm{~h}$ to give rise to orange solution of ligands. Zinc(II) acetate dehydrate $(0.44 \mathrm{~g}, 2.0 \mathrm{mmol})$ and $\mathrm{NaHCO}_{3}(0.17 \mathrm{~g}, 2.0 \mathrm{mmol})$ was added to the solution and stirred for 2 h. After filtration, yellow plate-like single crystals suitable for X-ray analysis were obtained. Yield $0.78 \mathrm{~g}$ (69.6\%). Anal. Calc. for $\mathrm{C}_{22} \mathrm{H}_{28} \mathrm{~N}_{2} \mathrm{O}_{2} \mathrm{Zn}$ : C, 63.23; H, 6.75; N, 6.70\%. Found: C, 63.62; H, 6.69; N, 6.64\%. IR $\left(\mathrm{KBr}, \mathrm{cm}^{-1}\right)$ : 541w, 769w, 869w, 980w, 1975w, 1112w, 1160s, 1212w, 1301w, 1413w, 1442s, 1518w, 1616s (C=N), 2934w, 2975w, 3054w, 3429s. m.p. 535 K (decomposition).

\subsection{Synthesis of Zn-Cyclohexyl}

To a solution of salicylaldehyde $(0.48 \mathrm{~g}, 4.0 \mathrm{mmol})$ dissolved in methanol $(70 \mathrm{~mL}), R$-1-cyclohexylethylamine $(0.29 \mathrm{~g}, 4.0 \mathrm{mmol})$ was added dropwise and stirred at $313 \mathrm{~K}$ for $2 \mathrm{~h}$ to give rise to orange solution of ligands. Zinc(II) acetate dehydrate $(0.44 \mathrm{~g}, 2.0 \mathrm{mmol})$ and $\mathrm{NaHCO}_{3}(0.17 \mathrm{~g}, 2.0 \mathrm{mmol})$ was added to the solution and stirred for $2 \mathrm{~h}$. After filtration, yellow plate-like single crystals suitable for X-ray analysis containing two methanol molecules as crystalline solvents were obtained. Yield $0.83 \mathrm{~g}$ (79.6\%). Anal. Calc. for $\mathrm{C}_{32} \mathrm{H}_{46} \mathrm{~N}_{2} \mathrm{O}_{3} \mathrm{Zn}$ (with one methanol molecules): C, 66.71; H, 7.95; N, 5.16\%. Found: C, 66.93; H, 7.86; N, 5.16\%. IR (KBr, $\left.\mathrm{cm}^{-1}\right)$ : 665w, 775w, 883w, 1030w, 1145w, 1303w, 1375s, 1453s, 1539w, 1614w (C=N), 1668w, 2324w, 2639w, 3407w. m.p. 567 K (decomposition).

\subsection{Synthesis of Zn-2-Naphtyl}

To a solution of salicylaldehyde $(0.48 \mathrm{~g}, 4.0 \mathrm{mmol})$ dissolved in methanol $(70 \mathrm{~mL}), R$-1-(2-naphtyl)ethylamine ( $0.69 \mathrm{~g}, 4.0 \mathrm{mmol}$ ) was added dropwise and stirred at $313 \mathrm{~K}$ for $2 \mathrm{~h}$ to give rise to orange solution of ligands. Zinc(II) acetate dehydrate $(0.44 \mathrm{~g}, 2.0 \mathrm{mmol})$ and $\mathrm{NaHCO}_{3}(0.17 \mathrm{~g}, 2.0 \mathrm{mmol})$ was added to the solution and stirred for $2 \mathrm{~h}$. After filtration, yellow precipitates were obtained. Unfortunately, single crystals suitable for Xray analysis could not be grown. Yield 0.90 g (72.2\%). Anal. Calc. for $\mathrm{C}_{38} \mathrm{H}_{28} \mathrm{~N}_{2} \mathrm{O}_{2} \mathrm{Zn}$ : C, 74.32; $\mathrm{H}, 5.25$; N, 4.56\%. Found: C, 73.94; H, 5.42; N, 4.71\%. IR $\left(\mathrm{KBr}, \mathrm{cm}^{-1}\right)$ : 476w, 601w, 668w, 720w 750w 824w, 862w, 1031w, 1146w, 1376s, 1460s, 1534w, 1608w (C=N), 1653s, 1700s, 2321w, 2355w, 2649w, 3745w. m.p. $615 \mathrm{~K}$ (decomposition).

\subsection{Physical Measurements}

Elemental analyses were carried out with a Perkin-Elmer 2400II CHNS/O analyzer at Tokyo University of Science. Thermal analysis was performed on a Rigaku TG8120 and $\alpha$-alumina was used as the reference sample (TG-DTA), where the heating rate was $10 \mathrm{~K} \cdot \mathrm{min}^{-1}$ in the range of $313-673 \mathrm{~K}$. IR spectra were recorded on a JASCO FT-IR 4200 plus spectrophotometer. UV-vis absorption spectra were recorded on a JASCO V-570 spectrophotometer at $298 \mathrm{~K}$. CD spectra were recorded on a JASCO J-820 spectrophotometer at $298 \mathrm{~K}$. Fluorescence spectra were recorded on a JASCO FP-6200 spectrophotometer at $298 \mathrm{~K}$. Photo-irradiation was carried out with $\mathrm{D}_{2}$ light source for 200 - $350 \mathrm{~nm}$ (with a visible cut filter) and Xe light source 350 - $800 \mathrm{~nm}$ (with a UV cut filter). Single crystals were glued on top of a glass fiber with an epoxy resin to measure the diffraction data. Intensity data were collected on a Bruker APEX2 CCD diffractometer with graphite monochromated MoK $\alpha$ radiation $(\lambda=0.71073 \AA$ ). Data analysis was carried out with a SAINT program package. The structures were solved by direct methods with a SHELXS-97 and expanded by Fourier techniques and refined by full-matrix least-squares methods based on $\mathrm{F}^{2}$ using the program SHELXL-97. An empirical absorption correction was applied by a program SADABS. All non-hydrogen atoms were readily located and refined by anisotropic thermal parameters. All hydrogen atoms were located at geometrically calculated positions and refined using riding models.

\subsection{Crystallographic Data for Zn-secBu (CCDC 812096)}

$\mathrm{C}_{22} \mathrm{H}_{28} \mathrm{~N}_{2} \mathrm{O}_{2} \mathrm{Zn}$, crystal size $0.15 \mathrm{~mm} \times 0.15 \mathrm{~mm} \times 0.12 \mathrm{~mm}, \mathrm{M}_{\mathrm{w}}=417.83$, tetragonal, space group $P 4_{3} 2_{1} 2, a=b$ 
$=7.3166(6) \AA, c=40.326(3) \AA, V=2158.8(3) \AA^{3}, Z=4, D_{\text {calc }}=1.286 \mathrm{mg} / \mathrm{m}^{3}, \mathrm{~F}(000)=880, \mathrm{R}_{1}=0.0392, \mathrm{wR}_{2}$ $=0.1264$ (2656 reflections), $S=1.046$, Flack parameter $=0.03(3)$. (where $\mathrm{R}_{1}=\Sigma|| \mathrm{F}_{\mathrm{o}}|-| \mathrm{F}_{\mathrm{c}}|/ \Sigma| \mathrm{F}_{\mathrm{o}} \mid \cdot \mathrm{R}_{\mathrm{w}}=\left(\Sigma \mathrm{w}\left(\left|\mathrm{F}_{\mathrm{o}}\right|\right.\right.$ $\left.\left.\left.-\mid \mathrm{F}_{\mathrm{c}}\right)^{2} / \Sigma \mathrm{w}\left|\mathrm{F}_{\mathrm{o}}\right|^{2}\right)^{1 / 2}, \mathrm{w}=1 /\left(\sigma^{2}\left(\mathrm{~F}_{\mathrm{o}}\right)+(0.1 \mathrm{P})^{2}\right), \mathrm{P}=\left(\mathrm{F}_{\mathrm{o} 2}+2 \mathrm{~F}_{\mathrm{c} 2}\right) / 3\right)$.

\subsection{Crystallographic Data for Zn-Cyclohexyl (CCDC 812095)}

$\mathrm{C}_{32} \mathrm{H}_{46} \mathrm{~N}_{2} \mathrm{O}_{4} \mathrm{Zn}$, crystal size $0.23 \mathrm{~mm} \times 0.15 \mathrm{~mm} \times 0.13 \mathrm{~mm}, \mathrm{M}_{\mathrm{w}}=590.09$, monoclinic, space group $P 2_{1}, a=$ 8.6963(14) $\AA, b=20.765(4) \AA, c=17.512(3) \AA, \beta=100.254(2)^{\circ}, V=3111.8(9) \AA^{3}, Z=4, D_{\text {calc }}=1.255 \mathrm{mg} / \mathrm{m}^{3}$, $\mathrm{F}(000)=1256, \mathrm{R}_{1}=0.0456, \mathrm{wR}_{2}=0.1144$ (12335 reflections), $S=0.790$, Flack parameter $=-0.007(11)$ (where $\left.\mathrm{R}_{1}=\Sigma|| \mathrm{F}_{\mathrm{o}}|-| \mathrm{F}_{\mathrm{c}}|| \Sigma\left|\mathrm{F}_{\mathrm{o}}\right| \cdot \mathrm{R}_{\mathrm{w}}=\left(\Sigma \mathrm{w}\left(\left|\mathrm{F}_{\mathrm{o}}\right|-\left|\mathrm{F}_{\mathrm{c}}\right|\right)^{2} / \Sigma \mathrm{w}\left|\mathrm{F}_{\mathrm{o}}\right|^{2}\right)^{1 / 2}, \mathrm{w}=1 /\left(\sigma^{2}\left(\mathrm{~F}_{\mathrm{o}}\right)+(0.1 \mathrm{P})^{2}\right), \mathrm{P}=\left(\mathrm{F}_{\mathrm{o} 2}+2 \mathrm{~F}_{\mathrm{c} 2}\right) / 3\right)$.

\subsection{Computational Methods}

All calculations were performed using the Gaussian 09W software Revision A.02 (Gaussian, Inc.) [34]. The gas phase geometry optimizations were carried out using PM6 functional. The vertical excitation energy was calculated with the ZINDO method based on the singlet ground state geometry.

\section{Results and Discussion}

\subsection{Characterization of Zn(II) Complexes}

Figure 2 and Figure 3 exhibit crystal structures of Zn-secBu and Zn-cyclohexyl, respectively. The asymmetric unit of Zn-cyclohexyl contains two crystallographically independent molecules and solvents that have been omitted from the figures. Unfortunately, suitable single crystals of Zn-2-naphtyl could not be obtained. Both $\mathrm{Zn}$-secBu and $\mathrm{Zn}$-cyclohexyl complexes afford a compressed tetrahedral trans-[ $\mathrm{ZnN}_{2} \mathrm{O}_{2}$ ] coordination geometry, which are similar to the analogous Schiff base Zn(II) complexes [24] [25]. Only for Zn-secBu complex, the central Zn atom is located on the center of symmetry. Most of them are within normal values for Schiff base Zn(II) or other related complexes [15] [24] [25]. No characteristic intermolecular interactions could be observed in the crystals.

Figure 4 depicts CD and absorption spectra for Zn(II) complexes. Because of absence of d-d bonds due to $\mathrm{d}^{10}$ electronic configuration, all absorption spectra appeared $\pi-\pi^{*}$ bands at 270 and $n-\pi$ bands at $360 \mathrm{~nm}$. While the corresponding CD bands were observed as split bands at 270, 330, and $380 \mathrm{~nm}$ reflecting the sign derived from chirality of amines.

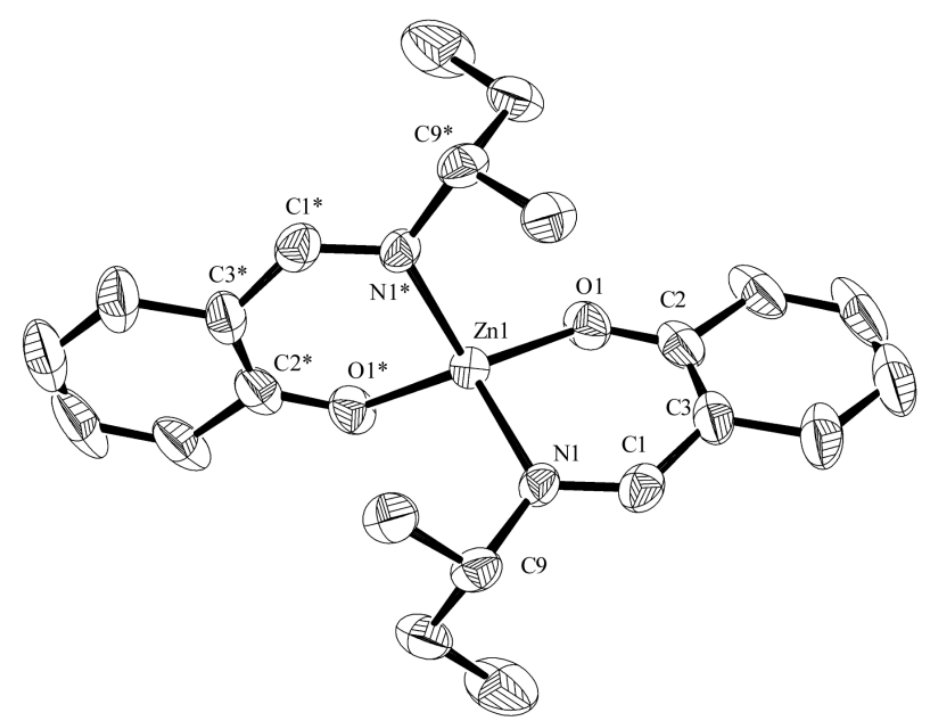

Figure 2. Crystal structures of Zn-secBu. Selected bond lengths $(\AA)$ and angles $\left({ }^{\circ}\right)$ are as follows: Zn1-O1 = 1.9129(18), Zn1-N1 = 2.014(2), C1-N1 = 1.282(6), O1-Zn1-O1* = 120.73(14), O1-Zn1-N1 = 96.85(9), O1-Zn1-N1* = 113.50(8), N1-Zn1-N1* = 116.82(13). 


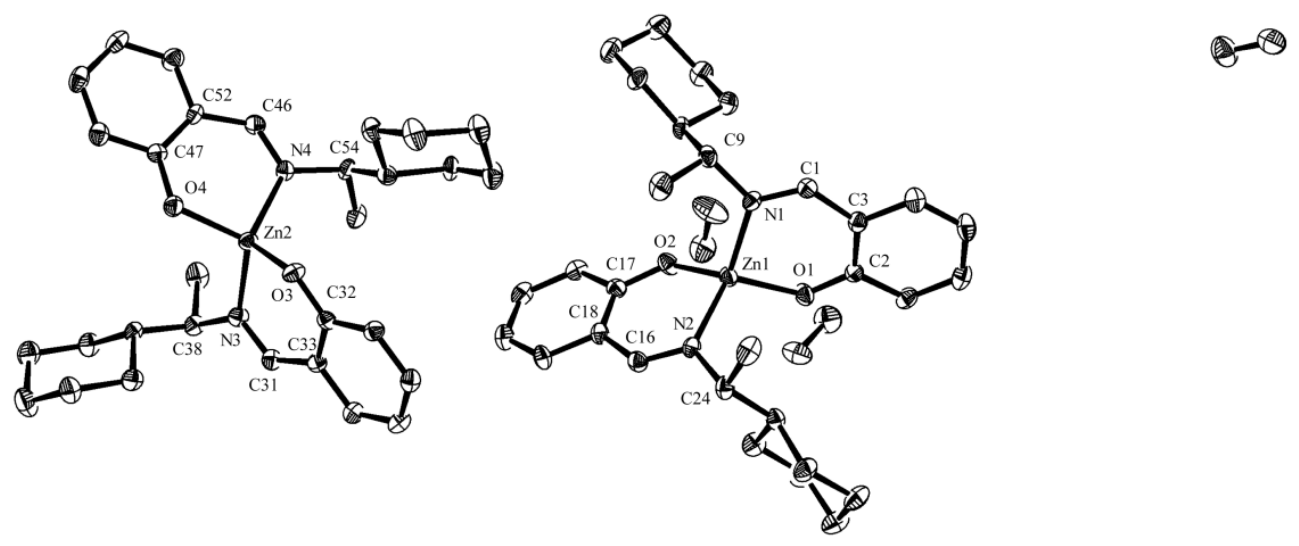

Figure 3. Crystal structures of Zn-cyclohexyl. Solvents are omitted for clarity. Selected bond lengths $(\AA)$ and angles $\left({ }^{\circ}\right.$ ) are as follows: Zn2-O4 = 1.921(3), Zn2-O3 = 1.937(3), Zn2-N3 = 2.002(3), Zn2-N4 = 2.004(3), Zn1-O2 = 1.909(3), Zn1-O1 = 1.928(3), Zn1-N2 = 1.995(3), Zn1-N1 = 2.001(3), N1-C9 = 1.468(6), N2-C16 = 1.292(6), O4-Zn2-O3 = 117.35(13), O4-Zn2-N3 = 111.21(15), O3-Zn2-N3 = 95.76(14), O4-Zn2-N4 = 96.92(15), O3-Zn2-N4 = 112.49(15), N3-Zn2-N4 = 124.68(12), O2-Zn1-O1 = 115.33(13), O2-Zn1-N2 = 96.75(15), O1-Zn1-N2 = 111.81(15), O2-Zn1-N1 = 111.48(15), O1-Zn1-N1 = 96.30(14), N2-Zn1-N1 = 126.37(12).

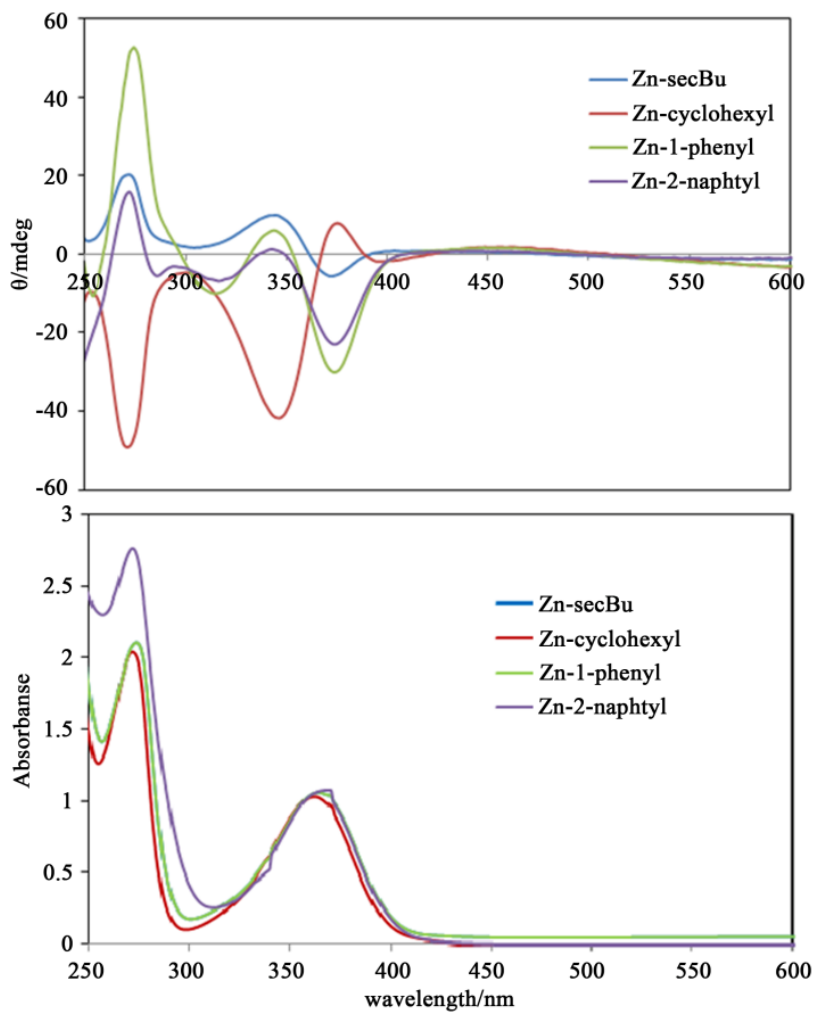

Figure 4. The $\mathrm{CD}$ and absorption spectra of $\mathrm{Zn}(\mathrm{II})$ complexes as $0.1 \mathrm{mM}$ methanol solutions. 
Figure 5 shows florescence spectra of $\mathrm{Zn}$ (II) complexes. The excitation wavelengths are set to be $\lambda_{\text {ex }}=270$ and $360 \mathrm{~nm}$ based on the absorbance spectra. For both excitation wavelengths, identical blue florescence peaks are observed around 440 - $450 \mathrm{~nm}$ for all complexes. Complex having more extended $\pi$-conjugate amine ligands (the order is Zn-2-naphtyl > Zn-1-phenyl > Zn-cyclohexyl $>$ Zn-secBu) show more intense peak.

In order to confirm assignments of transitions, we compared with experimental and calculated absorption spectra (not shown) and their comfortable consistency. For all complexes, main component of relatively weak $\mathrm{n}-\pi^{*}$ peaks around $380 \mathrm{~nm}$ and intense $\pi-\pi^{*}$ peaks around $250 \mathrm{~nm}$ may be transitions between two orbitals in salicylaldehyde moieties and $\mathrm{C}=\mathrm{N}$ groups, if any. For example, Figure 6(a) shows orbitals associated with $\pi-\pi^{*}$ or $\mathrm{n}-\pi^{*}$ transitions of $\mathrm{Zn}$-secBu. Predominant bands in a short wavelength region are assigned to be HOMO -1 to LUMO, HOMO to LUMO+1, and HOMO to LUMO+1 transitions. For Zn-cyclohexyl, $\pi$ - $\pi^{*}$ bands are similarly composed of relatively intense HOMO -3 to LUMO, HOMO -2 to LUMO+1, HOMO-1 to LUMO+2, and HOMO to LUMO+3 transitions, while $n-\pi^{*}$ bands are composed of HOMO -1 to LUMO, HOMO -1 to LUMO +1 , and HOMO to LUMO transitions. On the other hand, in the case of Zn-1-phenyl (and Zn-2-naphtyl) incorporatingconjugate systems in amine moieties, $\mathrm{n}-\pi^{*}$ bands are composed of intense HOMO -1 to LUMO, HOMO -1 to LUMO+1, and HOMO to LUMO+1 transitions in salicylaldehyde moieties only, while $\pi$ - $\pi^{*}$ bands are composed of LUMO+2 to LUMO+6, $\mathrm{LUMO}+3$ to $\mathrm{LUMO}+7, \mathrm{LUMO}+4$ to LUMO+8, and LUMO+5 to LUMO+9 transitions in not only salicylaldehyde but also $\pi$-conjugate amine moieties. Additionally, Figures 6(b)-(d) depict all ground and excited molecular orbitals which are associated with predominant $\pi-\pi^{*}$ or $\mathrm{n}-\pi^{*}$ bands for Zn-cyclohexyl, Zn-1-phenyl, Zn-2-naphtyl, respectively. Including the x-, y-, and z-coordinates, spatial distribution of molecular orbitals are also shown.
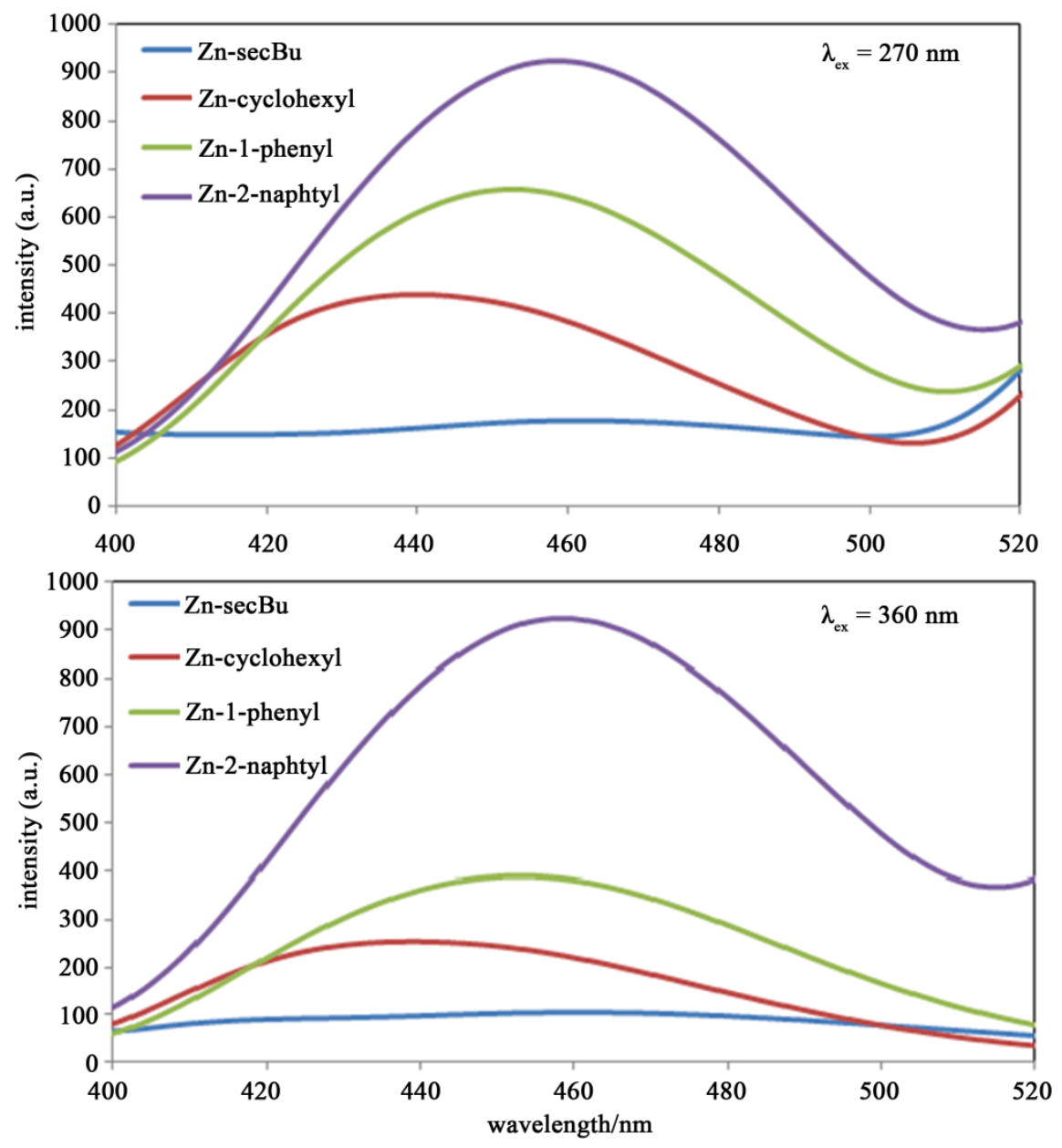

Figure 5. The fluorescence spectra $\left(\lambda_{\mathrm{ex}}=270\right.$ and $\left.360 \mathrm{~nm}\right)$ of $\mathrm{Zn}(\mathrm{II})$ complexes at $300 \mathrm{~K}$ as $0.0032 \mathrm{mM}$ methanol solutions. 

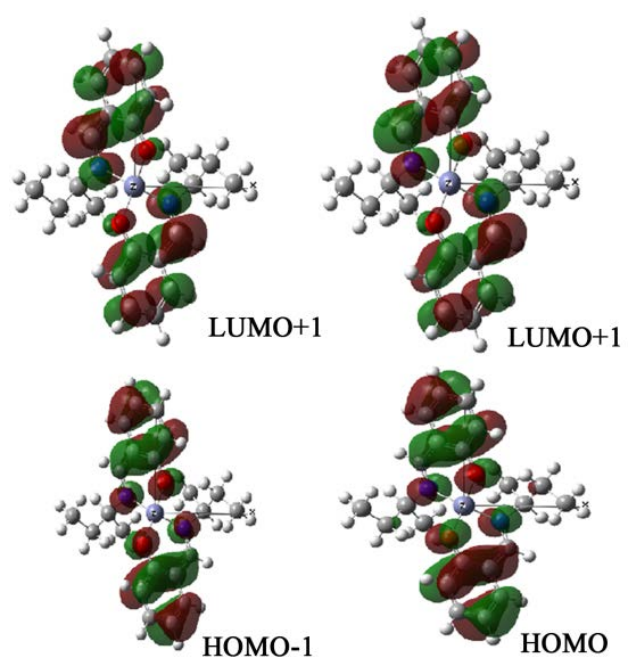

(a)
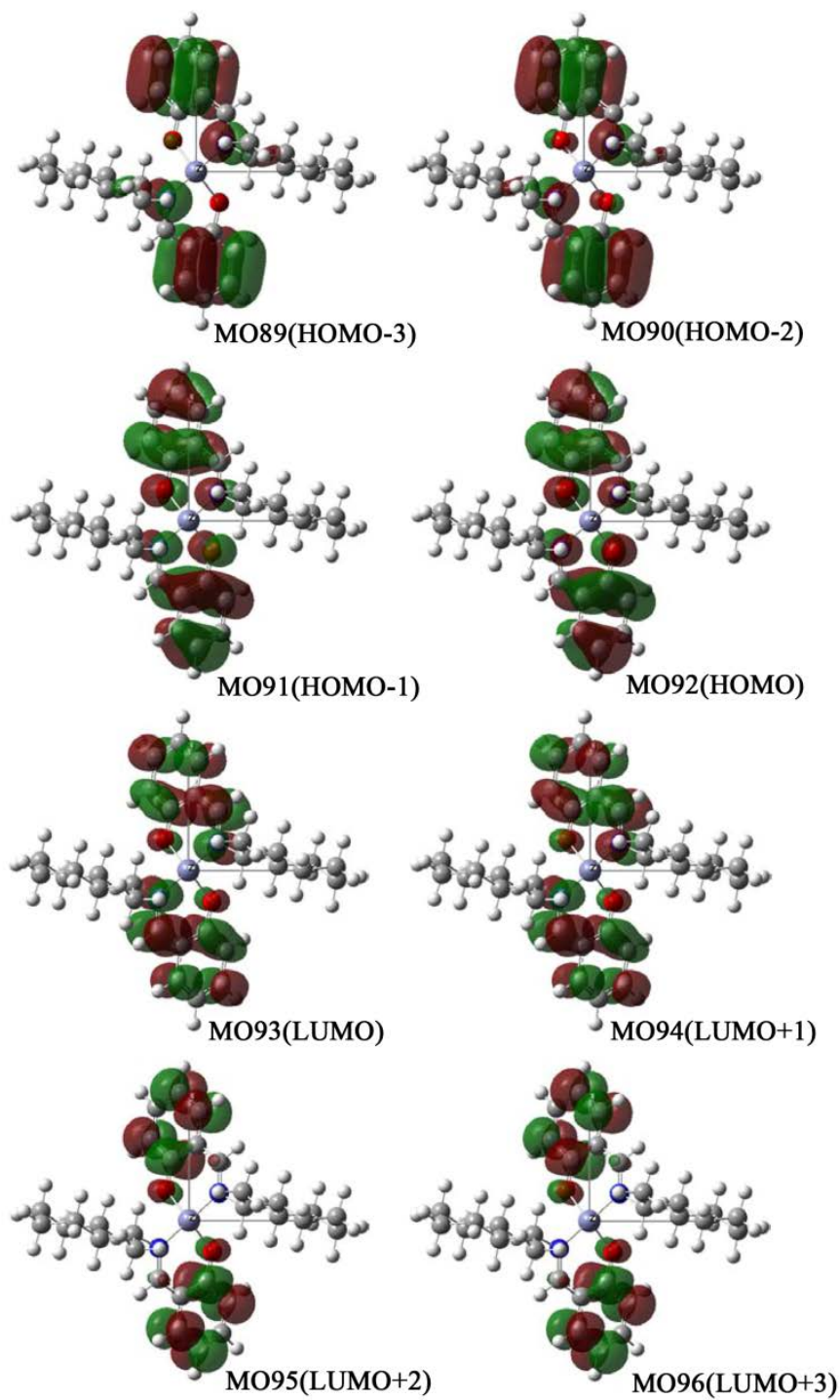

(b) 

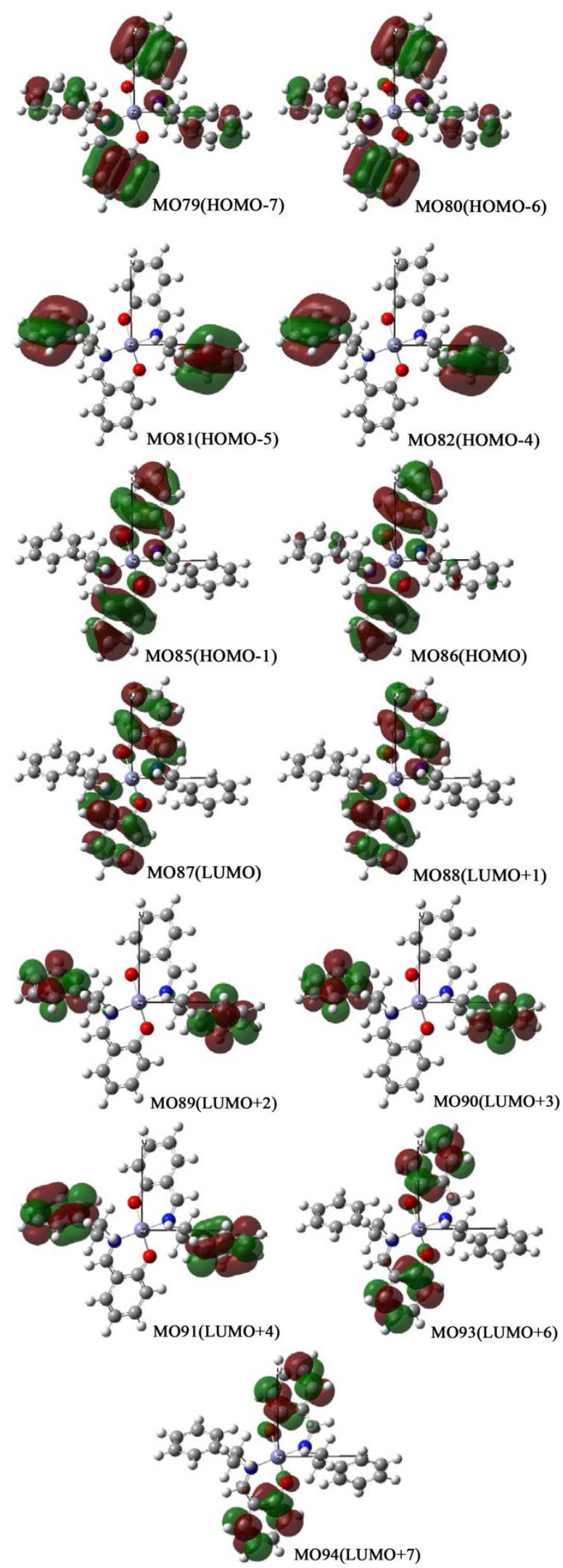

(c) 

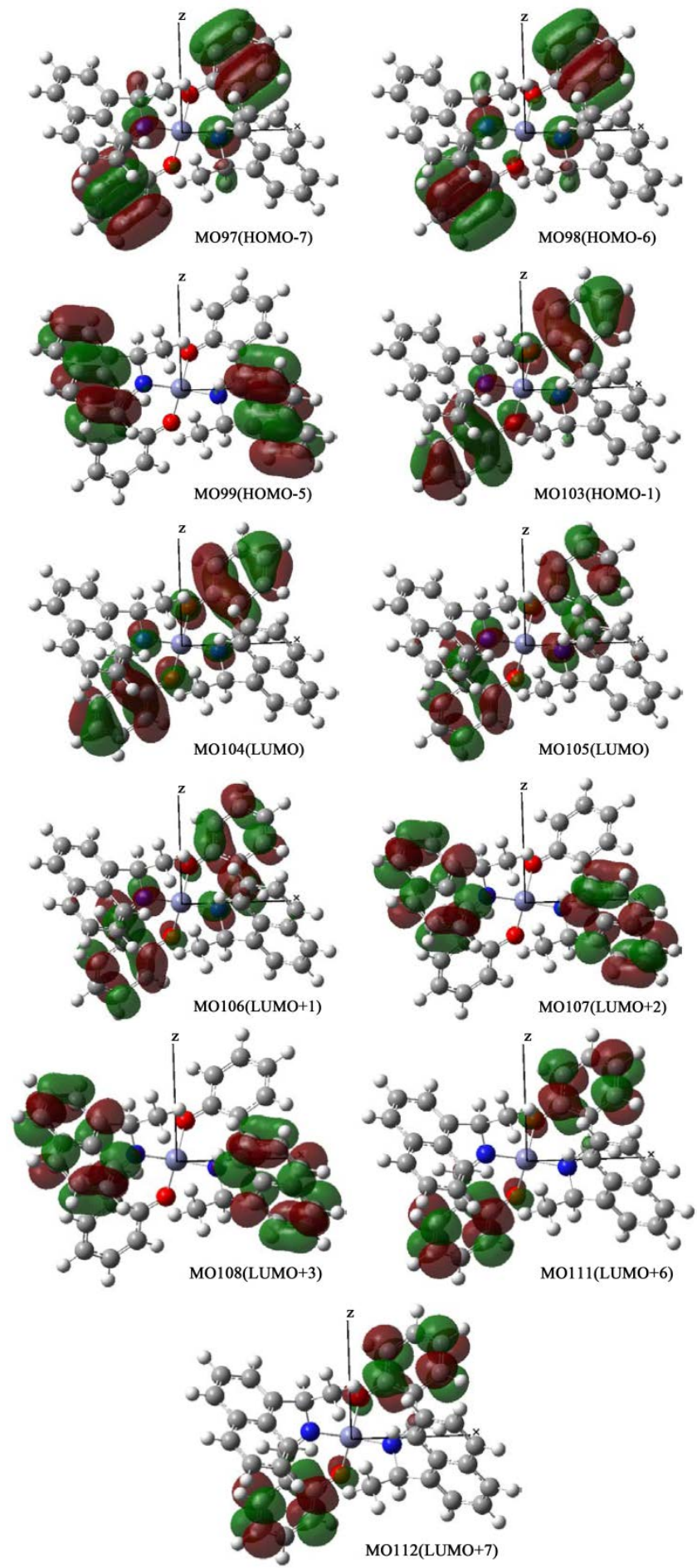

(d)

Figure 6. (a) Orbital surfaces of some important orbitals for $\pi-\pi^{*}$ or $n-\pi^{*}$ transitions of Zn-secBu calculated at ZINDO level based on the optimized geometry with Gaussian 09W; (b) Orbital surfaces of some important orbitals for $\pi-\pi^{*}$ or $n-\pi^{*}$ transitions of Zn-cyclohexyl calculated at ZINDO level based on the optimized geometry with Gaussian 09W; (c) Orbital surfaces of some important orbitals for $\pi-\pi *$ or $n-\pi *$ transitions of Zn-1-phenyl calculated at ZINDO level based on the optimized geometry with Gaussian 09W; (d) Orbital surfaces of some important orbitals for $\pi-\pi^{*}$ or $n-\pi^{*}$ transitions of Zn-2-naphtyl calculated at ZINDO level based on the optimized geometry with Gaussian 09W. 


\subsection{Fluorescence Intensity and Photoisomerization of Hybrid Systems of Spiropyrans and Zn(II) Complexes}

Also as shown Figure 1, SP exhibits reversible photochromism by UV and visible light irradiation, namely colourless SP (the closed-ring form) converts to reddish violet $(\lambda=533 \mathrm{~nm}$ ) MC (the open-ring form) exhibiting fluorescence peak at $612 \mathrm{~nm}\left(\lambda_{\mathrm{ex}}=533 \mathrm{~nm}\right)$ after UV light irradiation [26]-[28]. Therefore, we examined spectral features of hybrid systems of SP $(0.005 \mathrm{mM})$ and each Zn(II) complex $(0.1 \mathrm{mM})$ in methanol solutions before (initial state, abbreviated as "int") and after UV (abbreviated as UV) and visible (abbreviated as vis) light irradiation. Excitation wavelength for investigation was set as 270 and $360 \mathrm{~nm}$ suitable for fluorescence peak at $440 \mathrm{~nm}$ of Zn(II) complexes and $553 \mathrm{~nm}$ for fluorescence peak at $612 \mathrm{~nm}$ of MC. We could clearly observe both quenching of fluorescence intensity of $\mathrm{Zn}(\mathrm{II})$ complexes by MC or SP and their reversible changes accompanying by photoisomerization between MC and SP after UV and visible light irradiation.

Figure 7 shows fluorescence spectra of the hybrid system of SP and $\mathrm{Zn}$-secBu accompanying with photoisomerization. The spectra $\lambda_{\mathrm{ex}}=270 \mathrm{~nm}$ indicated stronger fluorescence peaks of MC (UV) than SP (int or vis), which suggested quenching of SP was more effective than that of MC in this hybrid system. In contrast, the spectra $\lambda_{\mathrm{ex}}=360 \mathrm{~nm}$ indicated stronger fluorescence peaks of SP than MC, which suggested that quenching of MC was more effective than that of SP in this hybrid system. Anyway, the spectra $\lambda_{\mathrm{ex}}=533 \mathrm{~nm}$ exhibits similar behavior to the sole SP solution, namely only MC (UV) shows fluorescence bands, which suggest quenching of fluorescence intensity for mixed solutions is effectively detectable by mixed Zn(II) complexes as hybrid systems.

Similar measurements have been carried out for other SP+Zn-cyclohexyl, SP + Zn-1-phenyl, and SP+ Zn-2-naphtyl hybrid systems. All systems exhibited similar behavior to that of the SP + Zn-secBu hybrid system except for band features due to substituted groups and the degree of quenching against SP.

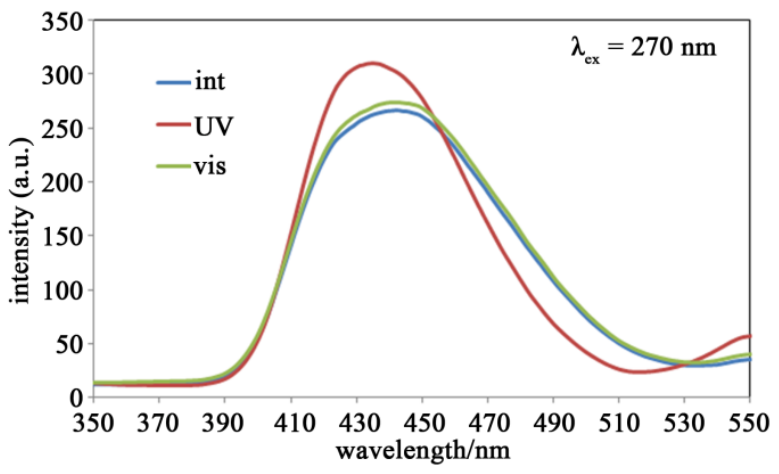

(a)

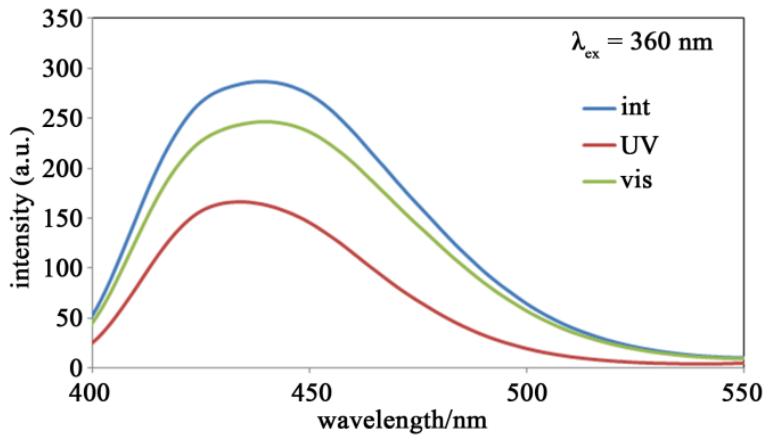

(b)

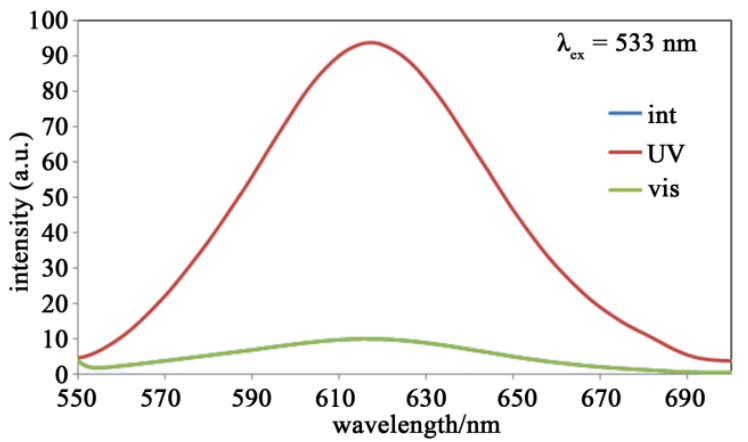

(c)

Figure 7. (a) The fluorescence spectra $\left(\lambda_{\mathrm{ex}}=270 \mathrm{~nm}\right.$ ) of SP (or MC) and Zn-secBu before (int) and after UV (UV) and visible (vis) light irradiation at $300 \mathrm{~K}$ in methanol solutions; (b) The fluorescence spectra $\left(\lambda_{\mathrm{ex}}=360 \mathrm{~nm}\right.$ ) of SP (or MC) and Zn-secBu before (int) and after UV (UV) and visible (vis) light irradiation at $300 \mathrm{~K}$ in methanol solutions; (c) The fluorescence spectra $\left(\lambda_{\mathrm{ex}}=533 \mathrm{~nm}\right.$ ) of SP (or MC) and Zn-secBu before (int) and after UV (UV) and visible (vis) light irradiation at $300 \mathrm{~K}$ in methanol solutions. 
Generally, both steric and ionic interactions should be considered as quenching factors of fluorescence spectra. The steric interaction is an interactive phenomenon that a fluorescent process is lost and the excitation energy of the fluorescent molecule becomes oscillation energy by intermolecular collision of molecules [29]-[33]. In view of SP, that MC (the open-ring form) is more bulky than SP (the closed-ring form) suggested effective quenching of MC. Moreover, in view of $\mathrm{Zn}$ (II) complexes, experimental results indicated that the magnitude of quenching is (bluky) Zn-2-naphtyl > Zn-cyclohexyl > Zn-1-phenyl > Zn-secBu (small). On the other hand, the ionic interaction is an interactive phenomenon that it is smoothly absorbed to the extinct medicine ion, and a fluorescent process is lost the ionic interaction bonds to the chromophore that has the excitation dipole moment of the fluorescent molecule, and deprives of the excitation electron that change into fluorescence. Because MC is a dipolar ion, quenching by this factor is also more effective than that of SP. In view of $\mathrm{Zn}$ (II) complexes, this factor of quenching is effective when SP (the quenching species) and $\mathrm{Zn}$ (II) complexes (the chromophores) contacts appropriately and the contribution the chromophores is high for excitation. Therefore, the absorption at $360 \mathrm{~nm}$ is thought to have received the influence of the ionic interaction greatly because it becomes only $\pi-\pi^{*}$ transitions of the $\mathrm{Zn}(\mathrm{II})$ complex (salicylaldehyde moieties). The absorption at $270 \mathrm{~nm}$ is thought that the influence is distributed from two or more transitions, and the effect of extinct of the ion interaction weakens. The ionic interaction may be one of the main factors of such quenching, and the excitation energy that originates in $\pi-\pi^{*}$ transitions of the salicylaldehyde moieties have been absorbed from the above-mentioned in the fluorescence of the complex by $360 \mathrm{~nm}$ in excitation wavelengths. Therefore, it is forecast that the MC structure with the dipolar ion has improved extinct more. It becomes impossible for two or more transitional states to exist, and to say the cause of extinct indiscriminately in the fluorescence of the complex by $270 \mathrm{~nm}$ in excitation wavelength. In the result of a measurement, a fluorescent peak shifts to the short wavelength side in all $\mathrm{Zn}$ (II) complexes in the state after UV light irradiation. A part of transition energy is adsorbed from this by SP by the ionic interaction with SP, other transitions are excited as it is, and the possibility of appearing as fluorescence may be thought [35] [36].

\subsection{Applications for Sensing Metal Ions}

After UV light irradiation to SP, MC can coordinate metal ions in solutions with acting the open-ring as chelate ligands. Therefore, we attempted to apply the hybrid systems [21]-[23] for sensing metal ions by using the intensity of characteristic fluorescence band of $\mathrm{Zn}(\mathrm{II})$ complexes. Doping $\mathrm{Zn}(\mathrm{II})$ and $\mathrm{Cu}(\mathrm{II})$ can be expected to increase or decrease the fluorescence intensity from ion-free SP hybrid systems mentioned above also by quenching mechanism. For example, for such experiments, hybrid systems of methanol solutions were prepared by mixing Zn-1-phenyl (0.002 mM), SP (0.005 mM) and free Cu(II) ion (0 mM, $0.005 \mathrm{mM}, 0.02 \mathrm{mM}, 0.035 \mathrm{mM}$, $0.05 \mathrm{mM}$ ). SP, MC, and free $\mathrm{Cu}(\mathrm{II})$ ion-doped MC showed absorption bands at 265 and $340 \mathrm{~nm}$ and at 265, 340, and $533 \mathrm{~nm}$, and at 265, 340, 533, and around $770 \mathrm{~nm}$ (weak and broad $\mathrm{Cu}(\mathrm{II})$ band), respectively. Among the four Zn(II) complexes, Zn-1-phenyl provided the best results because of suitable intermolecular interactions due to steric factors. It should be noted that free $\mathrm{Zn}(\mathrm{II}) \mathrm{MC}$ exhibited a fluorescence band at $617 \mathrm{~nm}\left(\lambda_{\mathrm{ex}}=553 \mathrm{~nm}\right)$. On the other hand, Zn(II)-coordinated MC show fluorescence at $619 \mathrm{~nm}\left(\lambda_{\mathrm{ex}}=553 \mathrm{~nm}\right)$. The resulting calibration curves fluorescence peaks ( $\lambda_{\mathrm{ex}}=360 \mathrm{~nm}$ ) vs doped $\mathrm{Zn}(\mathrm{II})$ and $\mathrm{Cu}(\mathrm{II})$ ions are shown in Figure 8 and Figure 9, respectively. As for the hybrid system of Figure 8, a mixed solution of Zn-1-phenyl and Zn(II)-coordinated MC, excess free $\mathrm{Zn}$ (II) ion enhanced the intensity of the fluorescence band at $440 \mathrm{~nm}$ of $\mathrm{Zn}-1$-phenyl $\left(\lambda_{\mathrm{ex}}=360\right.$ $\mathrm{nm}$ ) as a function of concentration of $\mathrm{Zn}(\mathrm{II})$ ions. Contrary to it, when $\mathrm{Cu}(\mathrm{II})$ ion was added as the hybrid system of Figure 9, SP, the intensity of $430 \mathrm{~nm}$ was decreased furthermore.

\section{Conclusions}

In summary, we synthesized some hybrid materials of chiral Schiff base Zn(II) complexes and SP. We observed their fluorescence and absorption spectra after UV and visible light irradiation. Reversible changes of fluorescence intensity of $\mathrm{Zn}$ (II) complexes could be observed, which reflects molecular structures of $\mathrm{Zn}$ (II) complexes. The enhancing or quenching fluorescence peaks of Zn(II) complexes are also confirmed by doping Zn(II) or $\mathrm{Cu}(\mathrm{II})$ ion into the hybrid systems and calibration curves as a function of concentration of doped metal ions. Consequently, assuming input (excitation light) and output (fluorescence bands) as follows, the hybrid systems can act as a molecular logic circuit summarized in Table 1 and Figure 10.

Furthermore, we have also investigated substituent effects about aldehyde moieties [37] and ion sensing with 


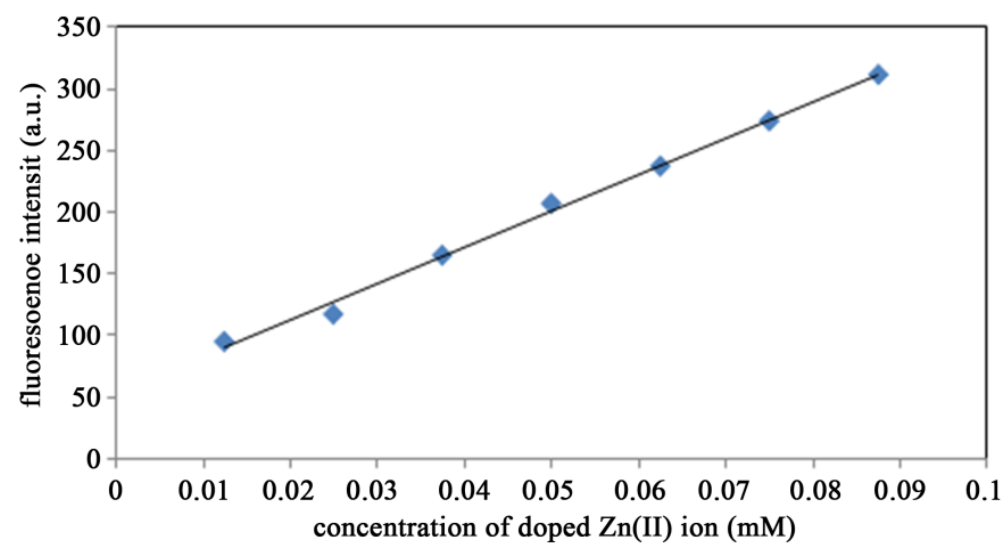

Figure 8. The concentration of doped $\mathrm{Zn}(\mathrm{II})$ dependence of fluorescence peaks at $440 \mathrm{~nm}\left(\lambda_{\mathrm{ex}}=360 \mathrm{~nm}\right) \mathrm{MC}$ and Zn-1-phenyl before (int) and after UV light irradiation at $300 \mathrm{~K}$ in methanol solutions.

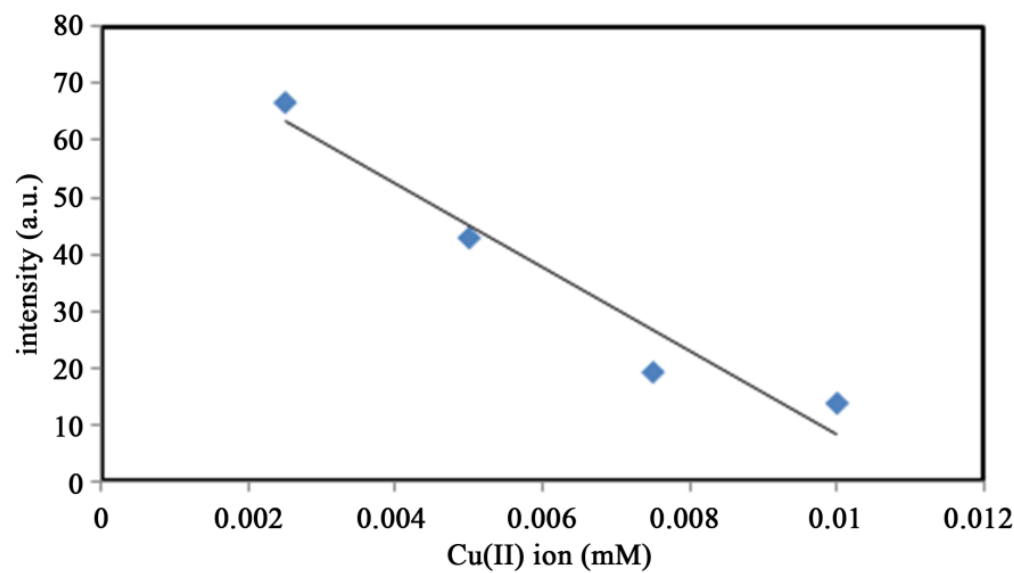

Figure 9. The concentration of doped $\mathrm{Cu}(\mathrm{II})$ dependence of fluorescence peaks at $440 \mathrm{~nm}\left(\lambda_{\mathrm{ex}}=360 \mathrm{~nm}\right) \mathrm{MC}$ and $\mathrm{Zn}$-1-phenyl before (int) and after UV light irradiation at $300 \mathrm{~K}$ in methanol solutions.

Table 1. A true or false table for the hybrid systems.

\begin{tabular}{|c|c|c|c|c|}
\hline \multicolumn{3}{|c|}{ Input } & \multicolumn{2}{|c|}{ Output } \\
\hline $\begin{array}{c}\text { Input } 1 \mathrm{UV} \\
\left(\lambda_{\mathrm{ex}}=270 \mathrm{~nm}\right)\end{array}$ & $\begin{array}{c}\text { Input } 2 \mathrm{UV} \\
\left(\lambda_{\mathrm{ex}}=360 \mathrm{~nm}\right)\end{array}$ & $\begin{array}{c}\text { Input } 3 \text { vis } \\
\left(\lambda_{\text {ex }}=553 \mathrm{~nm}\right)\end{array}$ & $\begin{array}{l}\text { Output } 1 \text { fluore } \\
\left(\lambda_{\mathrm{em}}=440 \mathrm{~nm}\right)\end{array}$ & $\begin{array}{l}\text { Output } 2 \text { fluore } \\
\left(\lambda_{\mathrm{mx}}=612 \mathrm{~nm}\right)\end{array}$ \\
\hline 0 & 0 & 0 & 0 & 0 \\
\hline 0 & 0 & 1 & 0 & 0 \\
\hline 0 & 1 & 0 & 0 & 0 \\
\hline 0 & 1 & 1 & 0 & 1 \\
\hline 1 & 0 & 0 & 1 & 0 \\
\hline 1 & 0 & 1 & 1 & 1 \\
\hline 1 & 1 & 0 & 0 & 0 \\
\hline 1 & 1 & 1 & 0 & 1 \\
\hline
\end{tabular}




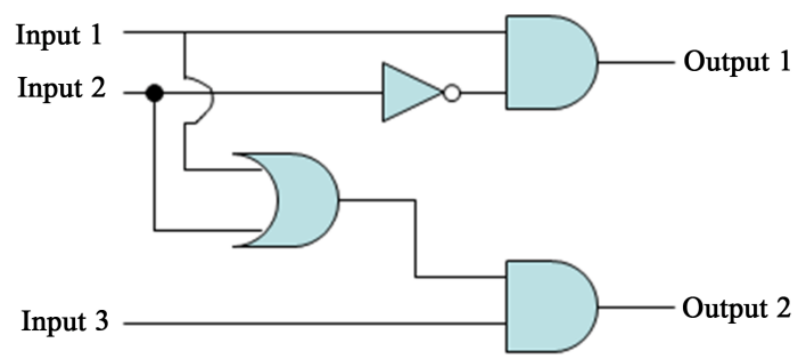

Figure 10. True or false logic circuits for the hybrid systems.

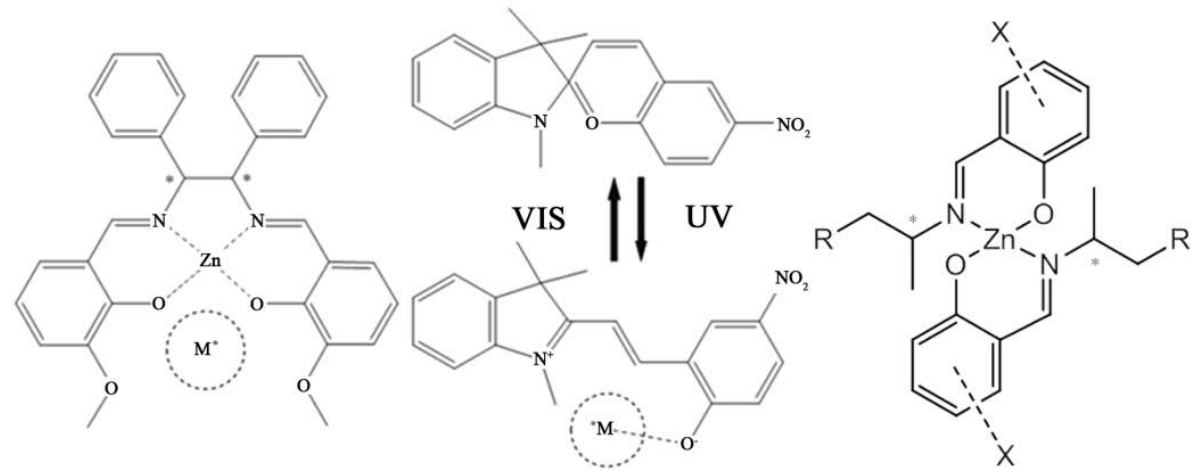

Scheme 1. The concept of the hybrid systems of Schiff base Zn(II) complexes and spiropyrans. (Left) salen-type, (Right) trans-type.

salen-type Schiff base Zn(II) complexes [38] except for this (original) report on substituent effects about amine moieties [39]. The concept of fluorescence detection and investigating factors (about substituents) of some hybrid systems is summarized in Scheme 1.

\section{References}

[1] Usinov, A.V. (1998) Solitons in Josephson Junctions. Physica D, 123, 315-329.

http://dx.doi.org/10.1016/S0167-2789(98)00131-6

[2] Szacilowski, K. (2008) Digital Information Processing in Molecular Systems. Chemical Reviews, 108, 3481-3548. http://dx.doi.org/10.1021/cr068403q

[3] Balzani, V., Credi, A. and Venturi, M. (2003) Molecular Logic Circuits. ChemPhysChem, 3, 49-59. http://dx.doi.org/10.1002/cphc.200390007

[4] Zong, G., Xian, L. and Lu, G. (2007) l-Arginine Bearing an Anthrylmethyl Group: Fluorescent Molecular NAND Logic Gate with $\mathrm{H}^{+}$and ATP as Inputs. Tetrahedron Letters, 48, 3891-3894. http://dx.doi.org/10.1016/j.tetlet.2007.03.139

[5] Qian, J., Qian, X., Xu, Y. and Zhang, S. (2008) Multiple Molecular Logic Functions and Molecular Calculations Facilitated by Surfactant's Versatility. Chemical Communications, 4141-4143. http://dx.doi.org/10.1039/b805876h

[6] Shiraishi, Y., Tokitoh, Y. and Hirai, T. (2005) A Fluorescent Molecular Logic Gate with Multiply-Configurable Dual Outputs. Chemical Communications, 5316-5318. http://dx.doi.org/10.1039/b510800d

[7] Budyka, M.F., Potashova, N.I., Gavrishova, T.N. and Lee, V.M. (2009) Reconfigurable Molecular Logic Gate Operating in Polymer Film. Journal of Materials Chemistry, 19, 7721-7724. http://dx.doi.org/10.1039/b908562a

[8] Baytekin, H.T. and Akkaya, E.U. (2002) A Molecular NAND Gate Based on Watson-Crick Base Pairing. Organic Letters, 2, 1725-1727. http://dx.doi.org/10.1021/ol005873c

[9] Konry, T. and Walt, D.R. (2009) Intelligent Medical Diagnostics via Molecular Logic. Journal of the American Chemical Society, 131, 13232-13233. http://dx.doi.org/10.1021/ja905125b

[10] Zhou, J., Arugula, M.A., Halamek, J., Pita, M. and Katz, E. (2009) Enzyme-Based NAND and NOR Logic Gates with Modular Design. The Journal of Physical Chemistry B, 113, 16065-16070. http://dx.doi.org/10.1021/jp9079052

[11] Pita, M., Strack, G., Mac Vittie, K., Zhou, J. and Katz, E. (2009) Set-Reset Flip-Flop Memory Based on Enzyme Reactions: Toward Memory Systems Controlled by Biochemical Pathways. The Journal of Physical Chemistry B, 113, 
16071-16076. http://dx.doi.org/10.1021/jp908291f

[12] Privman, V., Arugula, M.A., Halamek, J., Pita, M. and Katz, E. (2009) Network Analysis of Biochemical Logic for Noise Reduction and Stability: A System of Three Coupled Enzymatic AND Gates. The Journal of Physical Chemistry B, 113, 5301-5310. http://dx.doi.org/10.1021/jp810743w

[13] Margulies, D., Felder, C.E., Melman, G. and Shanzer, A. (2007) A Molecular Keypad Lock: A Photochemical Device Capable of Authorizing Password Entries. Journal of the American Chemical Society, 129, 347-354. http://dx.doi.org/10.1021/ja065317z

[14] Nishimura, G., Ishizumi, K., Shiraishi, Y. and Hirai, T. (2006) A Triethylenetetramine Bearing Anthracene and Benzophenone as a Fluorescent Molecular Logic Gate with Either-Or Switchable Dual Logic Functions. The Journal of Physical Chemistry B, 110, 21596-21602. http://dx.doi.org/10.1021/jp064131j

[15] Song, S. and Hu, N. (2010) pH-Controllable Bioelectrocatalysis Based on "On-Off” Switching Redox Property of Electroactive Probes for Spin-Assembled Layer-by-Layer Films Containing Branched Poly(Ethyleneimine). The Journal of Physical Chemistry B, 114, 3648-3654. http://dx.doi.org/10.1021/jp910048e

[16] Hod, O., Baer, R. and Rabani, E. (2005) A Parallel Electromagnetic Molecular Logic Gate. Journal of the American Chemical Society, 127, 1648-1649. http://dx.doi.org/10.1021/ja043366a

[17] Kikkeri, R., Grunstein, D. and Seeberger, P.H. (2010) Lectin Biosensing Using Digital Analysis of Ru(II)-Glycodendrimers. Journal of the American Chemical Society, 132, 10230-10232. http://dx.doi.org/10.1021/ja103688s

[18] Zhao, X. and Huang, C.Z. (2010) A Molecular Logic Gate for the Highly Selective Recognition of Pyrophosphate with a Hypocrellin A-Zn(II) Complex. Analyst, 135, 2853-2857. http://dx.doi.org/10.1039/c0an00431f

[19] Bonnet, C. S. and Gunnlaugsoon, T. (2009) Lanthanide Macrocyclic Quinolyl Conjugates as Luminescent Molecular Switches and Logic Gate Functions Using $\mathrm{HO}^{-}$and $\mathrm{O}_{2}$ as Inputs. New Journal of Chemistry, 33, 1025-1030. http://dx.doi.org/10.1039/b820372e

[20] de Sousa, M., Kluciar, M., Abad, S., Miranda, M.A., de Castro, B. and Pischel, U. (2004) An Inhibit (INH) Molecular Logic Gate Based on 1,8-Naphthalimide-Sensitised Europium Luminescence. Photochemical \& Photobiological Sciences, 3, 639-642. http://dx.doi.org/10.1039/b406415a

[21] Akitsu, T. and Einaga, Y. (2005) Synthesis, Crystal Structures and Electronic Properties of Schiff Base Nickel (II) Complexes: Towards Solvatochromism Induced by a Photochromic Solute. Polyhedron, 24, 1869-1877. http://dx.doi.org/10.1016/j.poly.2005.06.019

[22] Akitsu, T. and Einaga, Y. (2005) Syntheses, Crystal Structures and Electronic Properties of a Series of Copper(II) Complexes with 3,5-Halogen-Substituted Schiff Base Ligands and Their Solutions. Polyhedron, 24, 2933-2943. http://dx.doi.org/10.1016/j.poly.2005.06.018

[23] Akitsu, T. (2007) Photofunctional Supramolecular Solution Systems of Chiral Schiff Base Nickel(II), Copper(II), and Zinc(II) Complexes and Photochromic Azobenzenes. Polyhedron, 26, 2527-2535. http://dx.doi.org/10.1016/j.poly.2006.12.031

[24] Akitsu, T. and Itoh, T. (2010) Polarized Spectroscopy of Hybrid Materials of Chiral Schiff Base Cobalt(II), Nickel(II), Copper(II), and Zinc(II) Complexes and Photochromic Azobenzenes in PMMA Films. Polyhedron, 29, 477-487. http://dx.doi.org/10.1016/j.poly.2009.06.050

[25] Aritake, Y., Takanashi, T., Yamazaki, A. and Akitsu, T. (2011) Polarized Spectroscopy and Hybrid Materials of Chiral Schiff Base Ni(II), Cu(II), Zn(II) Complexes with Included or Separated Azo-Groups. Polyhedron, 30, 886-894. http://dx.doi.org/10.1016/j.poly.2010.12.015

[26] Guo, X., Zhang, D., Wang, T. and Zhu, D. (2003) Reversible Regulation of Pyrene Excimer Emission by Light and Metal Ions in the Presence of Photochromic Spiropyran: Toward Creation of a New Molecular Logic Circuit. Chemical Communications, 7, 914-915. http://dx.doi.org/10.1039/b301006f

[27] Raymo, F.M. and Giordani, S. (2001) Signal Processing at the Molecular Level. Journal of the American Chemical Society, 123, 4651-4652. http://dx.doi.org/10.1021/ja005699n

[28] Tian, Z., Stairs, R.A., Wyer, M., Mosey, J.M., Dust, J.M., Kraft, T.M. and Buncel, E. (2010) Spirooxazine to Merooxazine Interconversion in the Presence and Absence of Zinc: Approach to a Bistable Photochemical Switch. The Journal of Physical Chemistry A, 114, 11900-11909. http://dx.doi.org/10.1021/jp106501e

[29] Joseph, R., Chnta, J.P. and Rao, C.P. (2010) Lower Rim 1,3-Diderivative of Calix[4]Arene-Appended Salicylidene Imine $\left(\mathrm{H}_{2} \mathrm{~L}\right)$ : Experimental and Computational Studies of the Selective Recognition of $\mathrm{H}_{2} \mathrm{~L}$ toward $\mathrm{Zn}^{2+}$ and Sensing Phosphate and Amino Acid by [ZnL]. Journal of Organic Chemistry, 75, 3387-3395. http://dx.doi.org/10.1021/jo1004247

[30] Magri, D.C., Brown, G.J., McClean, G.D. and de Silva, A.P. (2006) Communicating Chemical Congregation: A Molecular and Logic Gate with Three Chemical Inputs as a "Lab-on-a-Molecule” Prototype. Journal of the American Chemical Society, 128, 4950-4951. http://dx.doi.org/10.1021/ja058295+ 
[31] Bozdemir, O.A., Guliyev, R., Buyukcakir, O., Selcuk, S., Kolemen, S., Gulseren, G., Nalbantoglu, T., Boyaci, H. and Akkaya, E.U. (2010) Selective Manipulation of ICT and PET Processes in Styryl-Bodipy Derivatives: Applications in Molecular Logic and Fluorescence Sensing of Metal Ions. Journal of the American Chemical Society, 132, 8029-8036. http://dx.doi.org/10.1021/ja1008163

[32] Evans, C. and Luneau, D. (2002) New Schiff Base Zinc(II) Complexes Exhibiting Second Harmonic Generation. Journal of the Chemical Society, Dalton Transactions, 83-86. http://dx.doi.org/10.1039/b104360a

[33] Zhao, L., Sui, D., Chai, J., Wang, Y. and Jiang, S. (2006) Digital Logic Circuit Based on a Single Molecular System of Salicylidene Schiff Base. The Journal of Physical Chemistry B, 110, 24299-24304. http://dx.doi.org/10.1021/jp062476w

[34] Frisch, M.J., Trucks, G.W., Schlegel, H.B., Scuseria, G.E., Robb, M.A., Cheeseman, J.R., Scalmani, G., Barone, V., Mennucci, B., Petersson, G.A., Nakatsuji, H., Caricato, M., Li, X., Hratchian, H.P., Izmaylov, A.F., Bloino, J., Zheng, G., Sonnenberg, J.L., Hada, M., Ehara, M., Toyota, K., Fukuda, R., Hasegawa, J., Ishida, M., Nakajima, T., Honda, Y., Kitao, O., Nakai, H., Vreven, T., Montgomery, Jr., J.A., Peralta, J.E., Ogliaro, F., Bearpark, M., Heyd, J.J., Brothers, E., Kudin, K.N., Staroverov, V.N., Kobayashi, R., Normand, J., Raghavachari, K., Rendell, A., Burant, J.C., Iyengar, S S., Tomasi, J., Cossi, M., Rega, N., Millam, J M., Klene, M., Knox, J.E., Cross, J.B., Bakken, V., Adamo, C., Jaramillo, J., Gomperts, R., Stratmann, R.E., Yazyev, O., Austin, A.J., Cammi, R., Pomelli, C., Ochterski, J., Martin, R.L., Morokuma, K., Zakrzewski, V.G., Voth, G.A., Salvador, P., Dannenberg, J.J., Dapprich, S., Daniels, A.D., Farkas, O., Foresman, J.B., Ortiz, J.V., Cioslowski, J. and Fox, D.J. (2009) GAUSSIAN 09, Revision A.1. Gaussian, Inc., Wallingford.

[35] Yeow, E.K.L. and Steer, R.P. (2003) Dynamics of Electronic Energy Transfer from the $\mathrm{S}_{2}$ State of Azulene to the $\mathrm{S}_{2}$ State of Zinc Porphyrin. Physical Chemistry Chemical Physics, 5, 97-105. http://dx.doi.org/10.1039/b208135k

[36] Speiser, S. and Shakkour, N. (1985) Photoquenching Parameters for Commonly Used Laser Dyes. Applied Physics B, 38, 191-197. http://dx.doi.org/10.1007/BF00697483

[37] Onodera, T. and Akitsu, T. (2013) Tuning of the Optical Properties of Chiral Schiff Base Zn(II) Complexes by Substituents. Polyhedron, 59, 107-114. http://dx.doi.org/10.1016/j.poly.2013.04.051

[38] Aonuma, M., Onodera, T., Morito, S., Wada, A. and Akitsu, T. (2013) Sensing of Metal Ions by Hybrid Systems of a Chiral Schiff Base Zn(II) Complex and Spiropyran. Journal of Applied Solution Chemistry and Modeling, 2, 96-104. http://dx.doi.org/10.6000/1929-5030.2013.02.02.3

[39] Miura, T., Onodera, T., Endo, S., Yamazaki, A., Akitsu, T. Asian Chemistry Letters. 
Scientific Research Publishing (SCIRP) is one of the largest Open Access journal publishers. It is currently publishing more than 200 open access, online, peer-reviewed journals covering a wide range of academic disciplines. SCIRP serves the worldwide academic communities and contributes to the progress and application of science with its publication.

Other selected journals from SCIRP are listed as below. Submit your manuscript to us via either submit@scirp.org or Online Submission Portal.
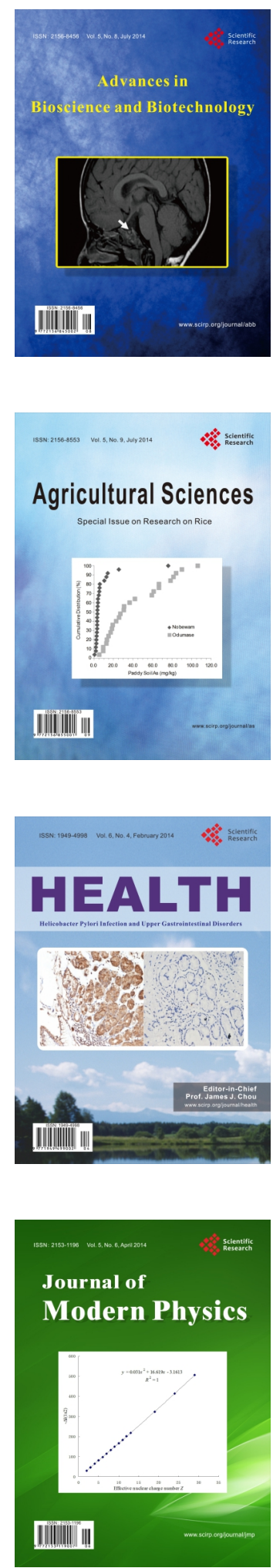
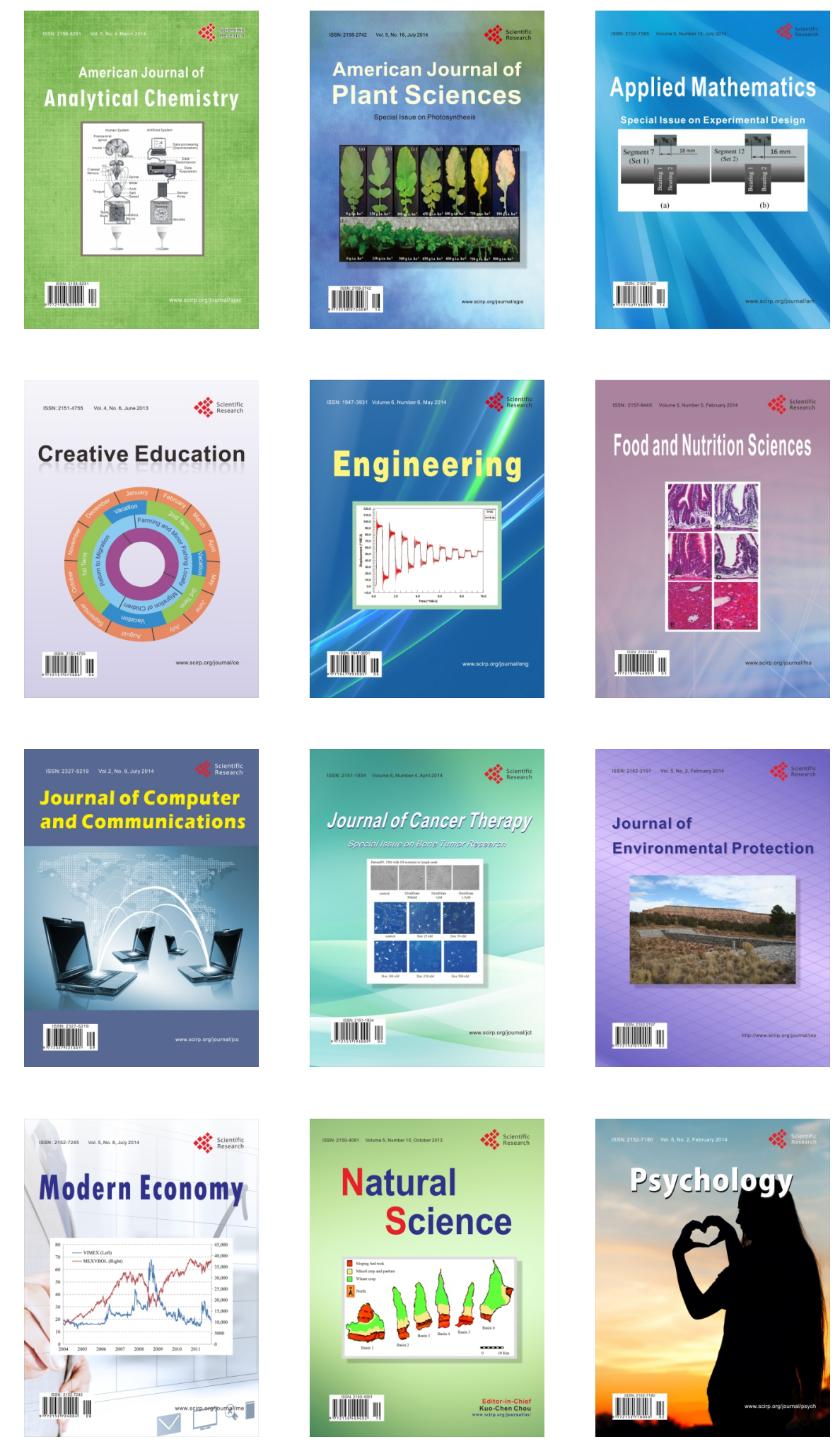